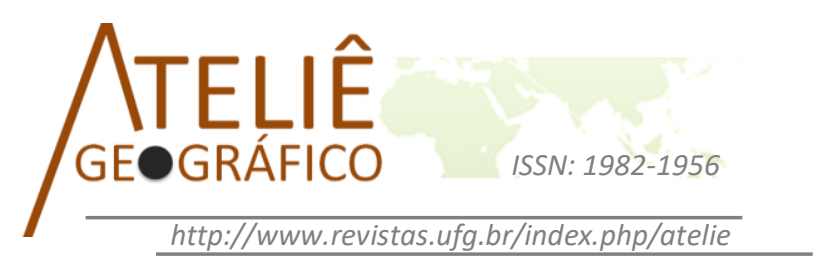

\title{
Análise da percepção e das práticas de Educação Ambiental em escolas de Curitiba/PR: subsídio à sensibilização socioambiental
}

\author{
Analysis of perception and practices of Environmental Education in \\ schools in Curitiba/PR: elements for socio-environmental awareness \\ raising
}

\section{Análisis de la percepción y prácticas de Educación Ambiental en escuelas Curitiba-PR: estimacion preventiva para la conciencia socioambientales}

\author{
Carla Luciane Blum Vestena \\ Universidade Estadual do Centro-Oeste (UNICENTRO) \\ clbvestena@gmail.com \\ Leandro Redin Vestena \\ Universidade Estadual do Centro-Oeste (UNICENTRO) \\ lvestena@gmail.com
}

\begin{abstract}
Resumo
Esse artigo apresenta a percepção de alunos de quarto e quinto ano do Ensino Fundamental, de escolas públicas e privadas, situadas próximas ao rio Belém, na cidade de Curitiba, Estado do Paraná sobre os problemas socioambientais e as práticas de Educação Ambiental desenvolvidas em suas escolas. Realizou-se uma entrevista, contendo três perguntas semiabertas e uma pergunta em que a resposta deveria ser na forma de um desenho. Conclui-se que a percepção dos alunos dos quartos anos é menos elaborada, em relação ao dos alunos de quintos anos. Os alunos apresentam pouco conhecimento dos problemas ambientais, apesar da grande maioria conhecer o rio Belém, embora alguns desconheçam o seu nome. A prática de Educação Ambiental é de caráter intraescolares, sendo relacionada aos conteúdos de animais e plantas, aos rios e a observação da natureza. As metodologias empregadas pelos professores na Educação Ambiental não estão alcançando seus objetivos propostos.
\end{abstract}

Palavras-chave: Percepção ambiental; Educação Ambiental; alunos.

\footnotetext{
Abstract

This paper presents the perception of fourth and fifth year students at state and private elementary schools located close to the River Belém in Curitiba-PR, Brazil, with regard to
} 
socio-environmental problems and environmental education practices undertaken in their schools. They were interviewed using three half-open questions and a fourth question to be answered in the form of a drawing. Results show that perception of fourth year students was lower than that of fifth year students. The students showed little knowledge of environmental problems, despite the majority of them knowing River Belém, although some of them do not know its name. Environmental Education at the schools is intramural and involves such subject matter as animals, plants, rivers and nature observation. The methodology used by teachers to provide environmental education is not reaching the proposed objective.

Keywords: Environmental Perception; Environmental Education; Students.

\section{Resumen}

En este artículo se muestra la percepción de alumnos de cuarto y quinto grado de las escuelas primarias, tanto públicas como privadas, ubicadas cerca del río Belém, en la ciudad de Curitiba, Estado de Paraná en cuanto a los problemas socio-ambientales. Además, se investigó la percepción de los mismos sobre las actividades de Educación Ambiental desarrolladas en sus escuelas. Se les ha realizado una entrevista con tres preguntas semiabiertas y una en la que la respuesta debe ser en la forma de un dibujo. Se concluye que la percepción (conocimiento) de los estudiantes de las salas de cuarto grado es menos elaborado en relación con los alumnos quinto grado. Los estudiantes presentan poco conocimiento de los problemas ambientales, a pesar que la mayoría conoce el río Belém, aunque algunos desconocen su nombre. La mayoría de las actividades de Educación Ambiental son de carácter intraescolar, estando relacionados los contenidos con los animales y las plantas, los ríos y la observación de la naturaleza. Las metodologías empleadas por los docentes de Educación Ambiental no están alcanzando los objetivos propuestos.

Palabras clave: Percepción ambiental; Educación Ambiental; estudiantes.

\section{Introdução}

No Brasil, com o passar dos anos, a Educação Ambiental (EA) tem se disseminado no ambiente escolar. Nos Parâmetros Curriculares Nacionais (PCNs), o meio ambiente é um dos temas transversais do currículo escolar que deve permear todas as áreas do ensino, na perspectiva de educar os alunos para a cidadania ambiental (BRASIL, 1997). A Lei Federal 9795/99 (BRASIL, 1999) - regulamentada pelo Decreto 4281/2002 (BRASIL, 2002) e que instituiu a Política Nacional de Educação Ambiental -, em seus Artigos 8 e 11 dispõe que todos os cursos de licenciatura, pósgraduação e atualização, devem incorporar a dimensão ambiental em seus currículos e programas.

As atuais Diretrizes Curriculares Nacionais para a Educação Ambiental (Resolução $n^{\circ} 2$ de 15 de junho de 2012), as quais implementam esta Lei, reafirmam em seu Art. 11 que a "dimensão socioambiental deve constar dos currículos de formação inicial e continuada dos profissionais da educação". Assim como que os "professores em atividade devem receber formação complementar em suas áreas de atuação, com o propósito de atender de forma pertinente ao cumprimento dos princípios e objetivos da Educação Ambiental" (BRASIL, 2012).

Neste contexto, a Educação Ambiental proposta às escolas deixa de ser vista como uma disciplina específica, mas como um tema transversal, em que os conteúdos 
socioambientais devem ser abordados em todas as disciplinas, de acordo com os anos e níveis de ensino (CARNEIRO, 2002).

Entretanto, apesar da crescente difusão da EA no processo educacional, ela geralmente apresenta-se fragilizada nas práticas pedagógicas, na medida em que estas não têm proporcionado transformações significativas na realidade. Para tanto, considera-se de extrema importância introduzir métodos de ensino de EA mais eficientes.

Neste sentido se faz necessário compreender como a criança percebe o meio ambiente. O desenvolvimento do pensamento da criança, segundo Piaget (1964), na função cognitiva abrange dois aspectos diferentes, o aspecto operativo e o aspecto figurativo. $\mathrm{O}$ aspecto figurativo compreende a percepção, a imitação, a imagem mental, o desenho etc., enquanto o aspecto operativo inclui operações e ações que levam de um estado para outro (transformações).

De modo geral, para o educador, os aspectos figurativos estariam subordinados aos operativos, nos adultos e em crianças em estágios mais avançados, enquanto que nas crianças menores as ações estariam subordinadas aos aspectos figurativos, por não possuírem os instrumentos necessários para o entendimento de tais operações. As crianças, antes de desenvolverem o aspecto operatório, necessitariam desenvolver o figurativo.

No aspecto figurativo, Piaget explica que a percepção seria um processo mental de interação do indivíduo com o ambiente por meio de mecanismos cognitivos. Esses mecanismos cognitivos incluem motivações, humores, necessidades, conhecimentos prévios, valores, julgamentos e expectativas. A percepção que as pessoas têm do meio seria proveniente, em grande parte, de suas experiências pessoais e seria uma visão subjetiva que, afinal, orientaria as suas ações no espaço (PIAGET, 1961; DEL RIO e OLIVEIRA, 1999).

As "imagens subjetivas de um indivíduo a respeito de um determinado espaço geográfico" (KOZEL, 2001, p.207) elaboradas por meio de processos perceptivos e mentais, são denominadas de mapas mentais. Estes, no caso, são construídos por informações e por experiência vivida, por isto, as crianças percebem melhor o espaço imediato, o seu espaço de vida, do que lugares distantes (GASPAR e MARIAN, 1975).

Para reconhecer o espaço vivido dos alunos, um dos instrumentos eficazes é a representação gráfica do meio ambiente, obtida por meio do desenho. Piaget e Inhelder (1981), em seus estudos, consideram o desenho como uma representação, que implicaria a construção de uma imagem diferente da própria percepção do objeto, e chamam a atenção para o fato de que nada prova que as relações espaciais, das quais é feita esta imagem, sejam do mesmo nível daquelas que correspondem à percepção. Nas pesquisas sobre desenho, foram consideradas as relações espaciais elementares que interviriam no espaço representativo ou, mais precisamente, no espaço gráfico. Não há 
dúvida de que o desenho constitui certo tipo de representação espacial, por isso o espaço gráfico é uma das formas do espaço representativo.

Os espaços vividos, cenários de experiências humanas, conforme Piaget (1975, p.404-405), são sentidos e compreendidos de maneiras individualmente distintas, por meio dos vínculos cognitivos e afetivos que são estabelecidos por intermédio dos mecanismos perceptivos. Estes estão distribuídos em dois planos: os efeitos do campo, ou interações imediatas entre elementos, como conjunto de atividades perceptivas, pois constituem a regulação das primeiras assimilações e anunciam, por sua vez, a reversibilidade das ações interiorizadas, ou reversibilidade da inteligência.

Todavia, o ambiente escolar, composto por sujeitos e objetos, apresenta diversos elementos naturais e construídos que são explorados pelos alunos mediante atividades perceptivas que se desenvolvem "naturalmente com a idade, em número e qualidade", salienta Piaget (1989, p.35). O resgate e a exploração das atividades perceptivas registradas do meio ambiente pelos alunos, por meio de representações, podem contribuir para o processo de desenvolvimento da tomada de consciência ambiental na sua própria ação (VESTENA et.al, 2009, p.250).

Assim sendo, a Educação Ambiental tem como foco central na prática escolar, sob premissas psicogenéticas, favorecer o desenvolvimento - em cada criança - de tomadas de consciência ambiental, orientada em termos de uma responsabilidade participativa e solidária em vista da gestão sustentável do meio.

Por isso, a tomada de consciência ambiental envolve a transformação dos esquemas de ação dos alunos, sobre seus ambientes de vida, em noções e em operações que são interiorizadas como informações, conceitos e conhecimentos. Nessa dinâmica integrada, o objetivo dos educadores está na construção de mudanças de atitudes e valores dos sujeitos para com o ambiente. (STOLTZ, 2008, p.128). Desse modo, a contribuição do educador, numa perspectiva piagetiana, está precisamente em possibilitar ao aluno refletir sobre a coordenação de suas ações na produção de determinados resultados, isto é, colocá-lo em conflito cognitivo.

Alunos da cidade de Curitiba-PR, apesar de viverem em uma cidade denominada "Capital Ecológica e Social", convivem com os mais variados problemas socioambientais, entre os quais se destaca o destino inadequado dos resíduos sólidos (lixo) e de efluentes domésticos (esgoto) e industriais que degradam a qualidade dos recursos hídricos.

Os rios que drenam a bacia hidrográfica do Belém, situada na área urbana de Curitiba, apresentam, em suas águas, elevadas taxas de deterioração, segundo a Suderhsa (2003). Eles, na realidade, já perderam sua configuração natural; aparecem canalizados e/ou retificados e desprovidos de vegetação ciliar. No leito fluvial e nas margens, são observados pontos de lançamento de efluentes e o descarte de resíduos sólidos a céu aberto. Tal situação é geradora de problemas socioambientais como 
doenças, alagamentos, inundações, mau-cheiro e outros que prejudicam a qualidade de vida.

Diante desse cenário, questiona-se: o rio Belém faz parte do imaginário dos alunos de quarto e quinto anos, do Ensino Fundamental de escolas públicas e privadas, situadas próximas ao rio? Qual a perceção ambiental dos alunos do $4^{\circ}$ e $5^{\circ}$ anos de escolas de ensino público e privado situadas próximas ao rio Belém, sobre os problemas socioambientais? Como eles percebem as atividades de Educação Ambiental (EA) desenvolvidas na escola?

Por esses questionamentos, verificou-se a perceção ambiental dos alunos de quarto e quinto anos, do Ensino Fundamental, de escolas públicas e privadas, situadas próximas ao rio Belém, sobre os problemas socioambientais, bem como, suas percepções acerca das atividades de Educação Ambiental desenvolvidas nestas instituições de ensino.

Este estudo tem importância sociopedagógica na medida em que a percepção das atividades de Educação Ambiental desenvolvidas nas escolas, bem como a dos alunos acerca do rio Belém, possibilita elaborar novas estratégias pedagógicas, que possam promover a sensibilização ambiental, em consonância com as diretrizes dos PCNs (BRASIL, 1997, p.32), que destacam que os trabalhos de EA devem partir "da visão que cada grupo social tem do significado do termo meio ambiente e, principalmente, de como cada grupo percebe o seu ambiente".

\section{Materiais e métodos}

Inicialmente foram delimitados os critérios de escolha das escolas: estar localizada próximo ao rio Belém e de suas nascentes - área urbana do município de Curitiba-PR, acessibilidade ou disponibilidade da escola para a pesquisa e possuir alunos de quartos e quintos anos do Ensino Fundamental. Por esses critérios, foram selecionadas quatro escolas denominadas de escolas E1 (pública - estadual) e E2 (pública - municipal), situadas no Bairro Mercês e Bom Retiro, respectivamente. E os Colégio C1 (particular) e o Colégio C2 (público - estadual) localizados no Bairro São Lourenço.

Posteriormente, foi escolhida, de forma aleatória, por sorteio, uma amostra de 156 alunos de quarto e quinto anos, do Ensino Fundamental, isto é $20 \%$ do número total de 780 alunos presentes nestes anos nas escolas/colégios selecionados. Por conseguinte, a amostra pesquisada compreendeu: 19 alunos (12,2\%) da E1, 31 alunos $(19,9 \%)$ da $\mathrm{E} 2,78$ alunos $(50 \%)$ do $\mathrm{C} 1$, e 28 alunos $(17,9 \%)$ do $\mathrm{C} 2$. O número de alunos da amostra das escolas pesquisadas não foi igualitário, pois a pesquisa não se voltou a uma amostra estatisticamente estabelecida, mas apenas uma amostra aleatória. A amostra oscilou entre as faixas etárias de oito a dez anos de idade e abrangeu alunos do sexo feminino e masculino, proporcionalmente. Assim como também uma amostra proporcional de alunos dos ensinos público e privado, ou seja, 78 alunos de colégio e 
escolas públicas de Ensino Fundamental e Médio, e 78 alunos de um colégio particular de Ensino Infantil, Fundamental e Médio.

Durante contato com os pedagogos de cada colégio e escola selecionada, foi agendado um horário para a realização das entrevistas, após obter consentimento dos pais de cada um dos(as) entrevistados(as) no primeiro semestre de 2013.

Foi utilizado o método clínico piagetiano, de acordo com as obras de Piaget (1926) e Delval (2002). O instrumento investigativo consistiu em três perguntas semiabertas e uma pergunta na qual a resposta por parte do aluno era a realização de um desenho, sendo:

1. Quando se fala do rio Belém, o que você pensa? Desenhe o que você imagina.

2. Você acha o rio Belém bonito e agradável? Se sim, por quê? Se não, por quê?

3. Tem algo que você pode fazer para melhorar o rio Belém? Se sim, o quê, por quê? Se não, por quê?

4. Em sua escola, você percebe atividades de Educação Ambiental? Se sim, quais? Se não, por quê?

Os desenhos foram utilizados por possibilitarem a apresentação de várias características, comuns a muitos assuntos, que não se revelam nas entrevistas, como as dimensões, a posição, o espaço ocupado, as cores etc., além do olhar, da proximidade, da atividade comum ou independente etc. A vantagem da utilização dessa técnica é que:

\footnotetext{
(...) frequentemente, e, sobretudo, no caso das crianças pequenas, elas conseguem expressar no desenho muitos elementos aos quais não se referem verbalmente. (...) o problema é que às vezes fica difícil interpretar os desenhos, então é melhor complementar o desenho com a entrevista (DELVAL, 2002, p.95-96).
}

Realizaram-se as entrevistas em uma sala cedida pela direção das escolas e colégios participantes da pesquisa, a duração de cada entrevista realizada variou de 20 a 35 min. Os materiais disponibilizados às crianças para a elaboração do desenho foram: uma folha de papel sulfite, lápis de escrever, borracha e uma caixa de lápis de cor, os quais ficaram dispostos a sua livre escolha.

As entrevistas foram gravadas e posteriormente transcritas, o que permitiu a elaboração das planilhas de perguntas e respostas, dadas na íntegra pelos alunos as perguntas semiabertas. A seguir, foram elaborados os protocolos, ou seja, quadros com as perguntas e conteúdos apresentados por cada aluno entrevistado. A análise dos dados foi desenvolvida com base em categorias geradas pelos conteúdos levantados nas respostas de cada aluno e do conjunto de alunos, tendo como fundamentação interpretativa o referencial teórico. 
A análise dos conteúdos apresentados nos desenhos foi categorizada conforme a proposta de Piaget e Inhelder (1993), envolvendo a compreensão dos conceitos de: "familiar" e "desconhecido", no que tange à percepção ambiental.

$\mathrm{Na}$ análise, os exemplos de respostas dadas às questões da entrevista e de desenho preservaram o anonimato dos alunos e instituições, sendo os mesmos substituídos por nomes fictícios, conforme recomendação do comitê de ética.

\section{Perceção do rio Belém: os desenhos dos alunos}

Nos desenhos, constatou-se que praticamente a metade dos alunos dos anos em destaque representou o rio Belém poluído (51,9\%), enquanto que 44,8\% representaram-no sem poluição. Na análise dos desenhos, ano por ano, percebeu-se que há diferença entre as percepções representadas pelos alunos destes anos. A maioria, $63,9 \%$ dos alunos de quarto ano, percebeu e representou o rio Belém como um rio sem poluição; já a maioria dos alunos de quinto ano $(67,8 \%)$ representou-o poluído.

Notou-se que 26,3\% dos alunos de quarto ano ilustraram o desenho indicando que o rio Belém está sem poluição, pela representação de águas limpas. Esta constatação confirmou que as verdadeiras condições ambientais do rio Belém são desconhecidas para a maioria dos alunos do quarto ano. Entretanto, os alunos de quinto ano representaram, em $31,5 \%$ dos seus desenhos, o elemento lixo, demonstrando familiaridade com as condições ambientais do rio Belém.

Sendo assim, os desenhos retratados pelos alunos, dos quarto e quinto anos do ensino Fundamental, demonstraram dois grupos específicos de representações perceptivas sobre o rio Belém, sendo estes caracterizados como:

a. $O$ desconhecido - não perceberam o rio Belém poluído e apresentaram alto índice de elementos naturais do meio ambiente como: as árvores, as flores, a vegetação nas margens, as aves, entre outros, contrapondo-se às reais condições do rio Belém (Figuras 1A e 1B).

b. $O$ familiar - perceberam o rio Belém poluído e representaram o alto índice de elementos característicos dessa categoria, como os seguintes: lixo, emissão de odores, animais mortos, entre outros. Identificaram-se as reais condições ambientais do rio Belém (Figuras $1 \mathrm{C}$ e $1 \mathrm{D}$.

Concordando com Piaget e Inhelder (1993), a partir desses grupos percebeu-se que o espaço de representação é dividido em duas partes: o familiar e o desconhecido. $\mathrm{Na}$ abordagem familiar, há elementos que são diretamente perceptíveis e podem ser representados no mapa mental pelo processo de assimilação, que envolve os processos mentais pré-existentes, as experiências pessoais e o conhecimento intelectual. Dessa elaboração, representada nos desenhos, evoluem as representações dos lugares ocasionando um determinado comportamento no indivíduo. Já, o desconhecido, há elementos que não são diretamente perceptíveis e acabam não representados no desenho pela ausência de familiaridade com o objeto representado. 


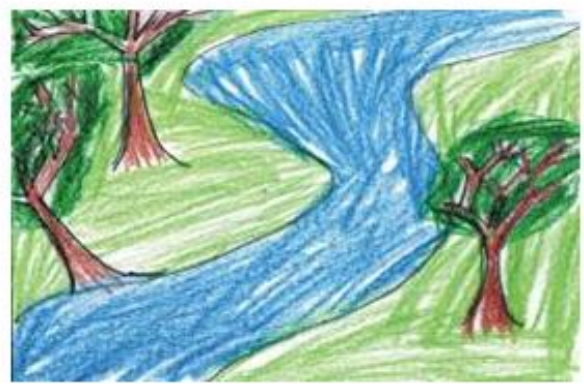

(A) - Luiz, 8 anos (E1 - 4 ANO). Categoria: sem poluição. Elementos: águas limpas, vegetação nas margens (árvores). Conteúdo: condições ambientais imaginárias.

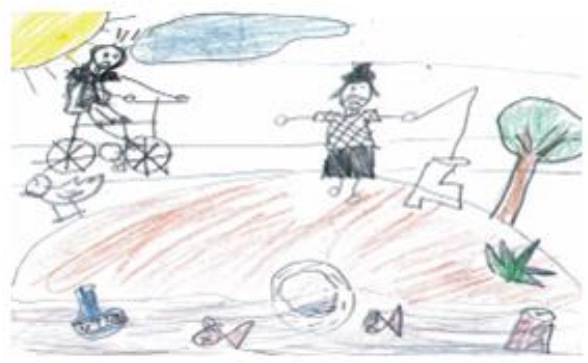

(C) - Cláudia, 9 anos (C2 - 5 ANO). Categoria poluído. Elementos: árvore, ave, rio, lixo, ciclovia e figuras humanas. Conteúdo: condições ambientais reais.

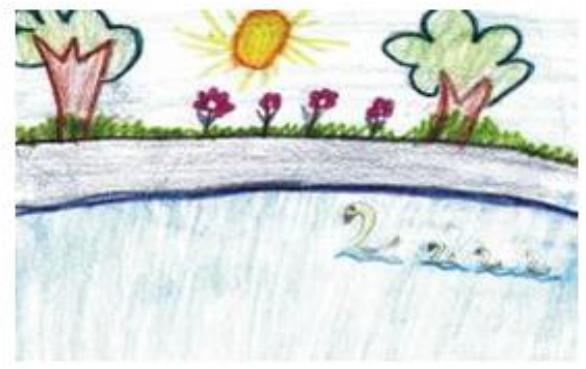

(B) - Natália, 9 anos - (C1 - 4 ANO). Categoria: sem poluição. Elementos: águas limpas, sol, árvores, flores e animais nadando. Conteúdo: condições ambientais imaginárias.

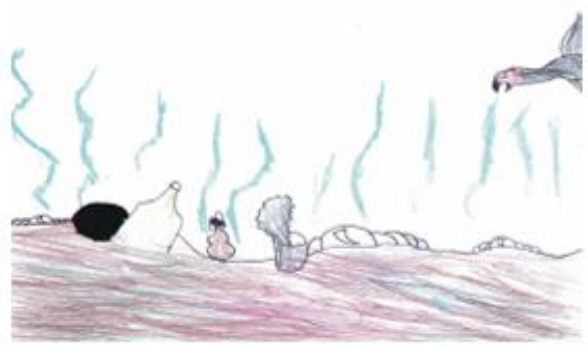

(D) - Carlos, 9 anos - (C1 - 5 ANO). Categoria: poluído. Elementos: lixo, ausência de vegetação, água poluída, emissão de odores, animal. Conteúdo: condições ambientais reais.

Figura 1: Tipos de desenhos realizados pelos alunos de quarto e quinto anos sobre o rio Belém.

Por esse referencial, notou-se que a grande maioria dos alunos de quinto ano $(67,8 \%)$ e de quarto ano do C2 $(33,3 \%)$ representaram alguns elementos característicos dos arredores da escola e do rio Belém, isto é, representam o familiar devido o processo de assimilação - os processos mentais pré-existentes, as experiências pessoais e o conhecimento intelectual, estando na etapa de processamento cognitivo interno em consonância às ideias de Souza (1998). O restante dos alunos de quarto ano da E2, da E1 e do $\mathrm{C} 1(63,9 \%)$ e $28,6 \%$ dos alunos no geral dos quintos anos representaram elementos desconhecido. Apenas dois alunos demonstraram muita familiaridade e, até mesmo, sensibilização ambiental, correspondente à etapa de avaliação de conduta e ação ambiental - etapa final do processo cognitivo ambiental. Aderindo ao que ressalta Piaget e Inhelder (1948), a partir do processo cognitivo ambiental é que evoluem as representações dos lugares preferenciais ocasionando um determinado comportamento no indivíduo.

Vale dizer que se concordou com Souza (1998, p.17), pois provavelmente estes resultados estão associados ao processo de cognição ambiental, especificamente à 
percepção de cada aluno e seus respectivos conhecimentos prévios dos arredores da escola e particularmente do rio Belém. Logo, é por meio desse contato direto com o meio ambiente que os alunos desenvolvem a percepção direta, ou seja, mediata e multissensorial, a qual é definida como um processo em que o indivíduo adquire as informações presentes no ambiente de forma seletiva. Durante este processo de apropriação das informações presentes no ambiente, o processamento cognitivo interno contribui principalmente na representação mental (mapeamento cognitivo ou mapa mental), relativa a um ambiente específico e suas condições ambientais naquele momento. É a partir dessa etapa, mais elevada da cognição, que ocorre a avaliação de conduta e ação ambiental, etapa final do processo. Esta é a etapa na qual o indivíduo, após perceber o ambiente, processa informações recebidas com aquelas que lhe são internas, forma sua representação interna e a avalia de acordo com seus valores e expectativas, determinando diretrizes para seu comportamento ambiental.

\section{A percepção do rio Belém: aspectos físicos apontados por alunos(as)}

A maioria $(58,9 \%)$ das crianças dos anos estudados considera o rio Belém não agradável porque se encontra poluído (33,3\%). Enquanto 27,7\% consideraram o rio Belém bonito e agradável porque o mesmo é "bonito" (10,9\%), e 19,2\% afirmaram que não conhecem o rio.

A análise dos sujeitos pesquisados apontou que a maioria dos alunos, 48,7\% (76 de 156 sujeitos) considerou não-agradável a presença do rio Belém, mas quando solicitados a justificarem a resposta 37,5\% (27 de 72 sujeitos) referenciaram aspectos agradáveis e 37,5\% (27 de 72 sujeitos) não-agradáveis, ou seja, uma igualdade. Isto demonstra que alguns alunos consideram a presença do rio Belém desagradável (negativa), mas utilizam uma justificativa positiva (agradável), mostrando contradição.

No que refere ao porquê de considerarem o rio Belém bonito e agradável ou não? - constatou-se que 58,3\% (21 de 72 sujeitos) dos alunos de quartos anos justificaram com aspectos não-agradáveis (negativos), enquanto, 30,6\% (11 de 72 sujeitos) apontaram aspectos agradáveis (positivos). Fato semelhante ocorreu com os alunos dos quintos anos, em que 61,9\% (52 de 84 sujeitos) consideraram os aspectos não-agradáveis e 16,7\% (14 de 84 sujeitos) os aspectos agradáveis.

Alguns aspectos decorrentes da descrição dos dados são relevantes, no caso dos alunos de quantos anos da E2, 38,5\% (05 de 13 sujeitos) consideraram o rio Belém agradável por ser bonito (justificativa superficial - fictícia) e (38,5\% - 05 de 13 sujeitos) afirmaram que não conhecem o mesmo, o que pode ser considerado como uma justificativa alienada do real. Entretanto, os alunos de quintos anos da escola anteriormente citada, consideraram não-agradável a presença do rio Belém pela poluição que este apresenta. Tais respostas condizem com o conhecimento concreto do real. Existe, portanto, uma diferença entre as respostas dos alunos de quartos anos e de 
quintos anos, sobre ser bonito e/ou poluído o rio Belém. Seguem, abaixo, alguns exemplos referentes às categorias acima citadas:

“Eu acho que é bonito”. E2 - $4^{\circ}$ ano. Categoria - aspectos agradáveis, subcategoria - é bonito. Conteúdo - superficialidade conhecimento fictício.

"Eu nunca vi, mas gostaria de conhecer". E2 - 4' ano - Categoria - não conhecem. Conteúdo - desconhecimento e alienação do real.

“Tem muito lixo”. E2 - $5^{\circ}$ ano. Categoria - aspectos não-agradáveis, subcategoria - é poluído. Conteúdo - conhecimento concreto do real.

O índice elevado da categoria - aspectos não-agradáveis atribuído ao rio Belém, provavelmente se refere à percepção peculiar de cada sujeito. Como prescreve Tuan (1980, p.91), a percepção varia de pessoa para pessoa, a maneira como avalia e registra o mundo, se diferencia de acordo com a cultura, o sexo, a idade e as experiências com o lugar, representando várias posturas de respeito, valorização, manejo e conservação dos recursos naturais.

A explicação da ambiguidade das respostas dadas pelos alunos ao quesito Por que o rio Belém é agradável ou não? Provavelmente ocorreu pelo fato de que a criança representa as coisas como as conhece e não como as vê. Em consonância com Piaget (1977, p. 164), se a criança representa as coisas como concebe, é claro que não pode percebê-las sem concebê-las, pois é necessário conhecer para perceber, se sensibilizar primeiramente, tomar consciência e finalmente aprender.

Nesse sentido, apesar de 48,7\% (76 de 156 sujeitos) dos alunos considerarem não-agradável a presença do rio Belém, as justificativas dadas não condizem com os percentuais apresentados anteriormente, em que 37,5\% (27 de 156 sujeitos) justificarem suas respostas com aspectos desagradáveis e 37,5\% (27 de 156 sujeitos) com aspectos agradáveis. Isto evidencia incerteza e artificialidade das repostas dadas pelos alunos dos anos estudados. O fato de não conhecer o rio Belém reflete-se na sensibilização ou não dos alunos que, por sua vez, é reflexo da falta de conhecimento sobre o mesmo.

$\mathrm{O}$ aspecto agradável apresentado pelo rio Belém de acordo com alunos de quartos anos da E2, caracteriza um conhecimento artificial e fictício do rio. Este não está concebido e, por conseguinte não há percepção, pois segundo Piaget (1993, p.207), para que haja percepção do rio é preciso concebê-lo. Pois, apesar de ser egocêntrica, incompleta e inconsciente de si mesma, a percepção também é inapta para descobrir a existência do ponto de vista próprio e situá-lo entre outros. Para tomar consciência do ponto de vista próprio é libertar-se do mesmo, ou seja, reconhecer o rio Belém e seus problemas ambientais, e libertar-se do processo de desconhecimento e alienação do real. Portanto, concordando com Piaget (1993, p.207), é preciso ir além da percepção para compreender e por fim agir, para tanto é necessária a tomada de consciência dos problemas ambientais. 
O desconhecimento e a alienação dos arredores da escola, do real, estão presentes nas respostas dadas pelos alunos de quartos anos $(63,6 \%)$ e quintos anos $(50,0 \%)$ da $E 1$, quando os mesmos afirmaram que não conhecem o rio Belém.

As opiniões dos alunos de quarto e quinto anos do C2 ficaram divididas entre o aspecto agradável - é bonito e desagradável - é poluído. Este fato demonstrou, novamente, a incerteza e artificialidade das respostas atribuídas sem conhecimento do rio Belém. Mais uma vez os resultados confirmam as ideias de Piaget (1993, p.207) de que a percepção é incompleta e inconsciente de si mesmo, e por isso, é preciso, conhecer o real (o rio Belém) para poder agir sobre ele.

Os alunos dos quartos anos $(38,9 \%)$ e os dos quintos anos $(57,1 \%)$ do $\mathrm{C} 1$ foram os que mais consideraram o rio Belém desagradável por estar poluído. Isto evidencia que os alunos têm conhecimento concreto - real dos problemas ambientais do rio Belém.

De acordo com os dados coletados anteriormente, observou-se que o conhecimento de alguns alunos sobre o rio Belém é referente a vários trajetos, e não especificamente ao trajeto próximo à escola. Provavelmente, estes alunos citaram outros trajetos por terem acesso aos mesmos, conhecendo-os. Assim, o conhecimento do rio Belém é pontual. Pois, como afirma Piaget (1993, p.207), a percepção, como já foi salientada, é egocêntrica, incompleta e inconsciente. Para superá-la, é preciso uma tomada de consciência, que envolve a tomada do ponto de vista próprio do fato, ou seja, das razões ou causas dos problemas ambientais, no caso mais específico dos problemas presentes nos arredores das escolas e do rio Belém.

A tomada de consciência envolve o conhecimento da realidade ambiental a ponto de superar a percepção e seus limites que a tornam incompleta é necessário elaborar um sistema de operações propriamente ditas para que haja a tomada de consciência. Isto é, renunciar pouco a pouco, aos falsos absolutos, ou seja, que os indivíduos veem como verdades, que se situam fora do contexto das relações construídas no próprio decorrer da experiência (PIAGET, 1977, p.164). Pois, inicialmente a experiência é expressa por gestos, desenhos e posteriormente por meio da linguagem. Sendo assim, essas expressões precisam ser valorizadas pelos professores que atuam principalmente nos anos iniciais do Ensino Fundamental, pois concordando com o mesmo autor, elas são essenciais para a estruturação do conhecimento das crianças na fase de oito a dez anos de idade, período das operações concretas.

\section{Sugestões apresentadas pelos alunos(as) para a melhoria da qualidade do rio Belém}

No quesito - $\mathrm{O}$ que você pode fazer para melhorar o rio Belém?- constatouse que 61,5\% (106 de 172 opiniões) dos alunos entrevistados apontaram ações isoladas, enquanto 22,6\% (39 de 172 opiniões) destacaram campanhas coletivas e 4,8\% (08 de 
172 opiniões) ações governamentais. Respectivamente, 54,0\% (93 de 172 opiniões) dos alunos de quarto e quinto anos responderam que para melhorá-lo é preciso não jogar lixo (ações isoladas), 11,0\% (19 de 172 opiniões) despoluir o rio Belém (campanhas coletivas) e 3,6\% (06 de 172 opiniões) tratamento das águas do rio e canalização (ações governamentais), dentre outras propostas.

Aproximadamente 58,3\% (07 de 12 opiniões) dos alunos de quartos anos da E1 afirmaram que não sabem quais seriam as propostas para melhoria do rio Belém, provavelmente pelo fato de que não o conhecerem. Outros 14,4\% (06 de 42 sujeitos) dos alunos de quartos anos do $\mathrm{C} 1$ apontaram como proposta para a melhoria do rio Belém as ações governamentais - saneamento, tratamento das águas do rio Belém e a canalização.

Ressalta-se que 38,9\% (07 de 18 opiniões) dos alunos de quintos anos da E2 foram igualmente atribuídas às propostas de ações isoladas - não jogar lixo e a campanhas coletivas - despoluir o rio Belém.

Já, 28,6\% (14 de 42 opiniões) dos alunos de quintos anos do C1 destacaram as campanhas coletivas como sugestão para a melhoria do rio Belém. Seguem abaixo alguns exemplos das categorias mencionadas anteriormente:

"Se ele for poluído em outro lugar, poderíamos colocar placas, avisando que não pode ir falando e espalhando a notícia”. (C1 $-5^{\circ}$ ano). Categoria campanhas coletivas, subcategoria - colocar cartazes ou placas. Conteúdo informação local e coletiva.

“Fazer greve para o Requião mandar limpar”. (C1 - 4 ano). Categoria ações governamentais, subcategoria - greve. Conteúdo - ações políticas em amenizar os problemas.

"Limpá-lo e dar lindos peixes". (E2 - 50 ano). Categoria - campanhas coletivas, subcategoria - despoluir o rio Belém. Conteúdo - ações de melhoria coletiva.

"Nada, pois moro longe”. (E2 - 5 ano). Categoria - sem opinião. Conteúdo - não comprometimento com o distante.

"Canalizando e despoluindo”. (E2 - $4^{\circ}$ ano). Categoria - ações governamentais, subcategoria - canalização. Conteúdo - soluções de cunho imediato.

“Não jogar lixo e não deixar ninguém jogar”. (C2 - 4 ano). Categoria ações governamentais, subcategoria - colocar fiscais para fiscalizar ações erradas. Conteúdo - controle das ações.

"Pedir aos políticos saneamento". (C1 - $4^{\circ}$ ano). Categoria - ações governamentais, subcategoria - solicitar saneamento dos políticos. Conteúdo amenizar e prevenir problemas.

"Falar para a prefeitura limpar ele todinho e conscientizar as pessoas não jogarem lixo no rio”. (C1 - $4^{\circ}$ ano). Categoria - ações governamentais, subcategoria tratamento do rio Belém e Educação Ambiental. Conteúdo - ação imediata e ações de mudança de conduta, e 
“Ensinado as pessoas a não jogar objetos no rio”. (C1 - 4 ano). Categoria - campanhas coletivas, subcategoria - conscientizar as pessoas. Conteúdo - ações de mudança de conduta.

A análise destacou que 54,0\% (93 de 172 opiniões) dos alunos de quarto e quinto anos atribuíram às ações isoladas de - não jogar lixo a melhoria do rio Belém. Tais sugestões são decorrentes do caráter egocêntrico dos alunos, de fato, se o ponto de vista da percepção é sempre egocêntrico, conforme Piaget (1993, p.207), as propostas de prevenção individual dadas como solução para a melhoria do rio Belém estão essencialmente ligadas ao indivíduo e sua ação no meio ambiente.

Posteriormente, os alunos de quarto e quinto anos sugeriram para a melhoria do rio Belém a ação de despoluir o rio Belém, referente a ações de campanhas coletivas que envolveriam os moradores, os alunos, os residentes próximo ao rio, entre outros.

No contexto geral, um número muito pequeno de alunos apontou para ações relacionadas às campanhas coletivas (colar cartazes, conscientizar as pessoas, conservar e despoluir o rio) e as ações governamentais (tratamento do rio Belém, canalização e solicitação aos políticos a providência de obras de saneamento e atividades de Educação Ambiental). Supostamente, as propostas sugeridas no sentido da ação imediata, local e coletiva de despoluição do rio Belém, refletem o grau de preocupação dos alunos em mobilizar a sociedade como um todo, na ação do resgate da qualidade hídrica do rio Belém.

De fato, a ação isolada não seria suficiente para obter resultados que necessitam de um tempo para se concretizarem e serem incorporados como atitudes e ações. Portanto, pensar em propostas para os problemas, especificamente no caso do rio Belém, envolve a educação ambiental ${ }^{1}$ como um processo participativo por meio do qual o indivíduo e a coletividade constroem valores sociais, adquirem conhecimentos, tomam atitudes, exercem competências e habilidades para a conquista e manutenção do meio ambiente ecologicamente equilibrado, já assinalado no Programa Nacional de Educação (PRONEA) de 1994, elaborado após a RIO -92 e reinterado

\section{Perceção das atividades de Educação Ambiental desenvolvidas nas escolas}

No geral, 80,1\% (125 de 156 sujeitos) dos alunos pesquisados perceberam que há atividades de EA desenvolvidas em suas escolas, enquanto 12,8\% (20 de 156 sujeitos) apontaram a inexistência dessa prática.

Notou-se que existe a unanimidade nas opiniões dos alunos de quartos anos do C2, ou seja, $100 \%$ dos mesmos afirmaram que existem atividades de Educação

\footnotetext{
${ }^{1}$ Entendem-se por educação ambiental “os processos por meio dos quais o indivíduo e a coletividade constroem valores sociais, conhecimentos, habilidades, atitudes e competências voltadas para a conservação do meio ambiente, bem de uso comum do povo, essencial à sadia qualidade de vida e sua sustentabilidade", segundo a Política Nacional de Educação Ambiental - Lei nº 9795/1999, Art 1º., BRASIL (1999).
} 
Ambiental na escola, enquanto, apenas 54,5\% dos alunos da E1 admitiram a existência de atividades de Educação Ambiental.

Neste quesito, também se verificou que os alunos de quintos anos do C2 foram os que mais apontaram a existência de atividade de Educação Ambiental na escola $(93,8 \%)$, e os da E2 os que menos referenciaram a presença destas.

Em contrapartida, quando se compararam os alunos dos anos das escolas pesquisadas, observaram-se diferenças entre os anos bem significativas, entre os alunos de quarto e quinto anos da E2 e da E1. Por exemplo, na E2, 44,4\% (08 de 18 sujeitos) dos alunos de quinto anos disseram que não existe atividade de Educação Ambiental na escola, enquanto, 92,3\% dos alunos de terceira série desta mesma escola afirmaram que existe atividade de Educação Ambiental na escola. No entanto, no C1 e no C2, as porcentagens entre os alunos de quarto e quinto anos apresentaram certa uniformidade. Tais constatações permitiram inferir que nas escolas - E2 e na E1 a prática da Educação Ambiental se dá de forma fragmentada, ou seja, em nível de turma e não em nível de escola (integrada).

Em relação à questão - quais são as atividades de Educação Ambiental desenvolvidas em sua escola? Visualizou-se que a maioria dos alunos referenciou categoria - intraescolar, subcategoria - atividades (45,6\% - 72 de 158 opiniões), e apenas 13,4\% (21 de 158 opiniões) à Categoria - extraescolar, subcategoria passeios/trilhas e visitas, 10,2\% (16 de 158 opiniões) à Categoria - extraescolar, subcategoria - plantio de árvores/horta, entre outras de menores porcentagens. Observou-se que as respostas atribuídas pelos alunos dos quartos anos que, de acordo com os percentuais obtidos, estão referidas à categoria - intraescolar, subcategoria atividades (38,5\% - E2, 45,5\% - E1,33,3\% - C2 e 57,9\% - C1). Nesta série, as subcategorias - projetos; coleta de água; ação de limpeza do rio; campanhas e panfletagens foram nulas.

Os alunos de quartos anos da E1 foram os únicos que apontaram a Categoria - intraescolar, subcategoria - atividades (45,5\% - 05 de 11 opiniões), além de 36,3\% (04 de 11 opiniões) não responderam e 9,1\% (01 de 11 opiniões) afirmarem nenhuma. $\mathrm{E}$ os alunos dos quartos anos o $\mathrm{C} 1$ foram os únicos a destacarem a Categoria intraescolar, subcategoria - desenhos (5,3\% - 02 de 38 opiniões).

Já, a maioria dos alunos dos quintos anos da E2 salientou a Categoria extraescolar, subcategoria - plantio de árvores/horta, ou seja, 27,7\% (5 de 18 opiniões), os alunos da E1 a Categoria - extraescolar, subcategoria - passeio/trilha/visitas $(50 \%$ 04 de 08 opiniões), os alunos do C.2 a Categoria - extraescolar, subcategoria - coletas de água (25\% - 04 de 16 opiniões) e os alunos do C1 a Categoria - intraescolar, subcategoria - atividades (66,6\% - 28 de 42 opiniões). Ou seja, em todas as escolas que participaram da pesquisa, as atividades intraescolares se sobrepõem às extraescolares.

A Categoria intraescolar, subcategoria - projetos foi apontada apenas pelos alunos dos quintos anos do C2 (6,2\% - 01 de 16 opiniões), o mesmo ocorreu com as 
categorias - extraescolar, subcategoria - coletas de água (conteúdo - análise do recurso natural) (25,0\% - 04 de 16 opiniões), ação de limpeza do rio (conteúdo - ação direta para amenizar os problemas) (12,6\% - 02 de 16 opiniões), entrevistas (conteúdo coleta de dados) (6,2\% - 01 de 16 opiniões) e panfletagens (conteúdo - sensibilização da comunidade) $(6,2 \%$ - 01 de 16 opiniões).

Pelo alto índice percentual a Categoria - intraescolar, subcategoria atividades, o qual foi o maior percentual geral dos entrevistados (45,6\% - 72 de 158 opiniões), desmembrou-se o tipo de atividades de Educação Ambiental realizadas nas escolas.

Por conseguinte, constatou-se que a maioria dos alunos não especificou as atividades intraescolares desenvolvidas na prática da Educação Ambiental, ou seja, 19,4\% (14 de 72 opiniões), apresentando assim um conteúdo implícito; e principalmente 16,6\% (12 de 72 opiniões) a Categoria - conteúdos trabalhados nas atividades, subcategoria - animais e plantas, conteúdo - exploração do recurso natural; 13,8\% (10 de 72 opiniões) a Categoria - conteúdos trabalhados nas atividades, subcategoria - rios, conteúdo - exploração do recurso natural; 9,7\% (07 de 72 opiniões) tarefas de Ciências, conteúdo - área do conhecimento científico; 7,0 \% (05 de 72 opiniões) lixo, conteúdo - produção de detritos.

Verificou-se também que apenas 4,2\% (03 de 72 opiniões) das atividades intraescolares referem-se à categoria - conteúdos trabalhados nas atividades, subcategoria - água, conteúdo - relacionada aos recursos hídricos.

No geral, os alunos dos quartos anos atribuíram maior índice percentual à categoria - conteúdos trabalhados nas atividades, subcategoria - animais e plantas (27,7\% - 10 de 36 opiniões), seguido pelas subcategorias - rios (22,2\% 08 de 36 opiniões); o lixo (13,7\% - 05 de 36 opiniões), entre outras, com menos índices percentuais. Já, para os alunos dos quintos anos 33,2\% (12 de 36 opiniões) não explicaram, seguido pela Categoria - conteúdos trabalhados nas atividades, subcategoria - tarefas de ciências com 19,7\% (07 de 36 opiniões).

Sendo assim, 80\% (04 de 05 opiniões) dos alunos de quartos anos da E2 apontaram que as atividades desenvolvidas em Educação Ambiental envolvem conteúdos, entre eles - animais e plantas e os rios. Já, 80\% (04 de 05 opiniões) dos alunos de quartos anos da E1 referiram-se aos conteúdos - lixo e 20,0\% (01 de 04 opiniões) aos rios. No que tange aos alunos de $4^{\circ}$ anos do $\mathrm{C} 2,50,0 \%$ (02 de 05 opiniões) os mesmos destacaram que os conteúdos trabalhados nas atividades de Educação Ambiental são referentes aos - animais e plantas e 25,0\% (01 de 04 opiniões) ao - lixo e rios. No $\mathrm{C} 1,22,7 \%$ (05 de 22 opiniões) dos alunos de quartos anos se referiram aos conteúdos - rios e 18,2\% (04 de 22 opiniões) aos - animais e plantas.

Respectivamente, 33,4\% (01 de 03 opiniões) dos alunos de quintos anos da E2 não especificaram quais seriam as atividades desenvolvidas em Educação Ambiental e 33,3\% (01 de 03 opiniões) afirmaram que as atividades envolvem os 
conteúdos - animais, plantas e os rios. Já, 100\% dos alunos da E1 não responderam a este quesito e $66,7 \%$ dos alunos do C2 destacaram que são feitas atividades de desenho e 33,3\% entrevista. Enquanto, 32,1\% (09 de 28 opiniões) dos alunos do C1 não especificaram quais seriam as atividades de Educação Ambiental desenvolvidas, 25,0\% (07 de 28 opiniões) apontaram que as atividades envolvem as tarefas de Ciências e 10,7\% (03 de 28 opiniões) o questionário. Alguns exemplos das categorias acima seguem logo abaixo:

“Às vezes Ciências e Filosofia para achar uma solução”. (C1 - 50 ano). Categoria - conteúdos trabalhados nas atividades, subcategoria - tarefas de Ciências e tarefas de Filosofia. Conteúdo - área do conhecimento científico.

"Sim, estamos estudando um pouco da Mata Atlântica, animais em extinção e muitas outras coisas". (C1 - $4^{\circ}$ ano). Categoria - conteúdos trabalhados nas atividades, subcategoria - Mata Atlântica. Conteúdo - tipo de vegetação.

"Sim, só que no ano passado, a gente plantou cenoura e muitas outras coisas". (E2 - 4 ano). Categoria - extraescolar, subcategoria - plantio de árvores/horta. Conteúdos - contato direto com o meio ambiente.

"Sim, coleta da água do rio e análise". (C2 - 5 ano). Categoria extraescolar, subcategoria - coleta de água. Conteúdo - análise dos recursos naturais.

"Sim, só os passeios e com os passeios a gente aprende coisas legais e interessantes que a gente não esquece." (E1- 5 ano). Categoria - extraescolar, subcategoria - passeios/ trilhas/visitas. Conteúdo - contato direto com o meio ambiente.

"Proteção ao meio ambiente e questionários". ( $\mathrm{C} 1$ - 5 ano). - Categoria produção escrita, subcategoria - questionários. Conteúdo - sistematização dos conteúdos. implícito.

“Em folha”. (C1 - 5 ano). Categoria - não especificaram. Conteúdo -

No que tange às atividades desenvolvidas, quase a metade dos alunos dos anos estudos referenciou que em EA são desenvolvidas "atividades", na grande maioria, intraescolares, associadas aos animais e plantas, a desenho de lixo e à observação da natureza, dando-se pouca ênfase às atividades extraescolares e de ações mobilizadoras da comunidade. Entretanto, verificou-se que os alunos dos quintos anos se diferenciaram dos quartos anos por relacionarem e realizarem suas atividades a partir de projetos que envolvem coleta de água, limpeza do rio, panfletagens e entrevistas. As atividades de quartos anos, ao contrário, são mais restritas ao ambiente intraescolar, com poucas atividades extraescolares e nenhuma ação de mobilização da comunidade.

Um grande número de alunos não especificou quais seriam as atividades desenvolvidas na prática da EA, o que denota que os conteúdos de EA estão implícitos 
em outras disciplinas e em atividades intraescolares. As atividades desenvolvidas com os alunos de quarto e quinto anos são relacionadas aos conteúdos trabalhados nas disciplinas de Ciências, Geografia e Filosofia. Atividades de produção visual (observação da natureza, desenho) e atividades de produção escrita (entrevistas, produções textuais) são pouco exploradas, principalmente nos quartos anos.

Ao analisar quais seriam as atividades desenvolvidas em Educação Ambiental, percebeu-se que 45,6\% (72 de 158 opiniões) dos alunos de $4^{\circ}$ e $5^{\circ}$ anos afirmaram que as atividades são intraescolares, e se referem a atividades, enquanto, 13,4\% (21 de 158 opiniões) apontaram que as atividades são extraescolares, envolvendo passeios/trilhas/visitas. A partir dessa constatação, realizou-se a análise específica sobre a Categoria atividades referenciada anteriormente por $45,6 \%$ dos alunos. Nesta, constatou-se que 19,4\% (14 de 72 opiniões) não especificaram quais seriam estas atividades desenvolvidas, enquanto $16,6 \%$ (12 de 72 opiniões) especificaram que as atividades desenvolvidas em Educação Ambiental estariam relacionadas aos conteúdos de animais e plantas, 13,8\% (10 de 72 opiniões) rios e apenas 4,2\% (03 de 72 opiniões) observação da natureza. Constatou-se, assim, que na prática da Educação Ambiental de acordo com os tais alunos, as atividades intraescolares são realizadas com maior frequência em detrimento das atividades extraescolares. Provavelmente, a pouca frequência das atividades extraescolares deve ser atribuída à proposta pedagógica das escolas que se diferenciam no que concerne às concepções de desenvolvimento e aprendizagem dos alunos, especialmente na fase das operações concretas - oito a dez anos de idade. Nesta fase, as crianças ainda não conseguem abstrair o conhecimento e a aprendizagem se dá em contato com os objetos reais do meio ambiente. Depois que as operações são obtidas, a experiência com o objeto não é mais primordial, pois a coordenação de ações pode desenvolver-se por si mesmo na forma de dedução e construção para estruturas abstratas.

Piaget (1964, p.176-186) diz que a influência desempenhada pela experiência dos efeitos do meio físico sobre as estruturas da inteligência é essencial para desenvolver as estruturas cognitivas. Mas, só ela não é suficiente para desenvolver a aprendizagem, e em consonância com este mesmo autor é preciso valorizar as experiências físicas - compreender o ato de agir sobre os objetos e tirar algum conhecimento sobre os objetos pela abstração dos mesmos; e da experiência lógicomatemática, que é uma experiência de ações do sujeito e não dos objetos em si, portanto, ambas são necessárias para que possa haver operações.

A não-especificação das atividades desenvolvidas por $19,4 \%$ dos alunos de quarto e quinto anos estão relacionadas à falta de significação das atividades, as incoerências das respostas dadas pelos alunos, como demonstra Piaget (1977, p.164) quando afirmam que uma percepção fora do contexto das relações construídas no próprio decorrer da experiência dos mesmos ocorre pelo fato de os alunos terem pouco 
contato com o meio que os cerca, especificamente os arredores das escolas e o rio Belém.

O baixo índice de 2,5\% de atividades desenvolvidas de maneira intraescolar relacionadas à produção de desenhos está associado, provavelmente, ao desmerecimento e não uso da mesma atividade, apesar desta ser importante, pois em conformidade com Piaget (1967, p.164), as crianças, ao desenhar, expressam as coisas tais como as que conhecem e não tais como as veem, pois a ação refletida é expressa inicialmente por gestos, desenhos e posteriormente por meio da linguagem.

Aderindo às ideias de Cuello Gijón (1992, p. 52), são nos anos iniciais do Ensino Fundamental ( $1^{\circ}-5^{\circ}$ anos $)$ que a apreensão das questões relativas ao meio deve iniciar de maneira progressiva e gradual, respeitando a maturidade cognitiva e afetiva. $\mathrm{O}$ enfoque dado deve seguir a construção do conceito de meio, de forma contínua; levando em consideração os diferentes níveis de formulação dos conceitos básicos ligados à percepção do meio. Para tanto, é preciso que o professor compreenda que este processo de conhecimento do meio ambiente é, sobretudo, uma construção social que passa pela percepção e leitura do próprio sujeito e é mediada pela cultura em questão.

$\mathrm{Na}$ descrição das atividades desenvolvidas, a Educação Ambiental apareceu referenciada nas tarefas de Ciências, principalmente, Geografia e Filosofia, não sendo referenciadas pelas demais áreas do conhecimento. Provavelmente isto está ocorrendo pela falta de aplicabilidade dos Parâmetros Curriculares Nacionais (1997, p. 49), especificamente no exemplar - meio ambiente. Este é um dos temas transversais do currículo escolar, que deve estar permeando todas as áreas de ensino na perspectiva de educar os alunos para a cidadania ambiental. Em consonância com Carneiro (2002, p.41), a Educação Ambiental deve ser vista dentro do enfoque de conteúdos socioambientais a serem trabalhados em todas as disciplinas - em proporção adequada de abrangência e aprofundamento nas diversos anos e níveis de ensino. Pois, desde os primeiros anos as atitudes para com o meio ambiente devem ser formadas para incorporar ao caráter e comportamento dos alunos em prol de futuras ações responsáveis para com o meio ambiente. Para tanto, adere-se à proposta de Malhadas (2001, p.08), o qual afirma que a efetivação da prática de Educação Ambiental envolve a elaboração de projetos que coloquem em aplicação os princípios estabelecidos pela Agenda 21.

Constatou-se que apenas $0,6 \%$ dos alunos do $\mathrm{C} 2$ salientaram que as atividades de Educação Ambiental são desenvolvidas a partir de projetos. Neste sentido, verificou-se que a escola possui projetos de Educação Ambiental, apesar destes serem ainda pouco representativos dentro do contexto global.

Embora exista uma proposta de ensino da Educação Ambiental, a partir de projetos no $\mathrm{C} 2$, o que se percebeu é que a maioria das atividades de Educação Ambiental ainda se limita às atividades intraescolares, envolvendo as disciplinas (Geografia, Ciências, Filosofia, entre outras) que apresentam maior afinidade com o 
tema ambiental, caracterizado por produção de escrita, questionário e desenho sobre os animais e plantas.

\section{Conclusões e considerações finais}

Pelos objetivos propostos, é possível inferir que a perceção acerca do meio ambiente, analisado com base nos desenhos dos alunos de quartos anos demonstrou-se pouco elaborado e ainda muito desconhecido, pois o rio Belém foi representado sem poluição, enquanto para os alunos de quintos anos, mostrou-se mais elaborado e familiar, ao passo que representaram o mesmo poluído.

Quanto à representação do rio Belém e de acordo com cada escola pesquisada, há disparidade em relação a percepção dos alunos pesquisados, ou seja, na E1 e a E2 praticamente é inexiste a sensibilização ambiental em relação ao rio Belém, porque os alunos não percebem as reais condições ambientais do mesmo. Porém, nos C2 e C1, a sensibilização ambiental é de aproximadamente $50 \%$, pois são os que percebem as reais condições do rio Belém, dentre estes os alunos de quintos anos apresentam maior grau de sensibilização ambiental ficando em torno de $70 \%$, visto que são os que mais demonstram conhecimento figurativo, ao expõrem minuciosamente as condições sociofísicas do rio Belém e indicarem iniciativas minimizadoras das questões ambientais.

Há contradição sobre a existência de atividades de Educação Ambiental na escola e o conhecimento das mesmas, visto que $45,6 \%$ dos alunos de $5^{\circ}$ anos afirmaram existir atividades de caráter intraescolares, porém $16,6 \%$ justificaram que estariam relacionadas aos conteúdos de animais e plantas, 13,8\% rios e apenas 4,2\% observação da natureza.

Houve baixo índice de $2,5 \%$ de atividades desenvolvidas de maneira intraescolar relacionadas à produção de desenhos, muito embora, saiba-se que ao desenhar, as crianças expressam as coisas tais como as que conhecem e não tais como as veem, pois a ação refletida é expressa inicialmente por gestos, desenhos e posteriormente por meio da linguagem. Além de ser o desenho uma forma de expressão relevante ao processo educativo dos anos iniciais do Ensino Fundamental e, por conseguinte, merece-se mais atenção dos educadores.

De fato, a maior incidência de atividades de Educação Ambiental nas escolas analisadas se restringe às atividades intraescolares, em detrimento das extraescolares apontadas por $13,4 \%$ dos alunos investigados.

A utilização de desenhos nos anos iniciais do Ensino Fundamental, o estudo investigativo do meio ambiente proveniente em aulas de caráter exploratórias de campo, não tem sido uma prática corriqueira na Educação Ambiental. A nãoexploração do aspecto figurativo do conhecimento ficou explícita nos resultados desta pesquisa. 
Portanto, há de se repensar qual a epistemologia que tem embasado as práticas da Educação Ambiental em tais escolas investigadas. Como seria o objetivo e a finalidade da EA nestas escolas. Diante do que se expôs anteriormente, sugere-se que estudos futuros possam ser realizados a fim de deslumbrar estas questões, no intuito de contribuir para a discussão desta temática, vista a complexidade e atualidade da mesma, ainda há muito a se fazer.

\section{Referências Bibliográficas}

BRASIL. Ministério da Educação. Departamento de Educação Ambiental. ProNEA Programa Nacional de Educação Ambiental. Ministério do Meio Ambiente, Coordenação Geral de Educação Ambiental. 3 ed. Brasília: MMA, DF, 1994.

BRASIL. Ministério da Educação. Secretaria da Educação Fundamental. Parâmetros Curriculares Nacionais: Meio Ambiente, Saúde/Secretária de Educação Fundamental. Brasília: MEC/SEF, 1997.

BRASIL. Lei no 9.795 de 27 de abril de 1999. Dispõe a Educação Ambiental, institui a Política Nacional de Educação Ambiental e dá outras providências. Diário Oficial [da] República Federativa do Brasil, Brasília, DF, n. 79, 28 abr. 1999.

BRASIL. Resolução $n^{o} 2$ de 15 de junho de 2012. Estabelece as Diretrizes Curriculares Nacionais para a Educação Ambiental. Brasília: Ministério da Educação/Conselho Nacional de Educação/Conselho Pleno, 2012. Disponível em: $<$ http://portal.mec.gov.br/index.php?option=com_content $\&$ view=article $\&$ id $=17810 \&$ It emid=866> . Acesso em: 22 fev. 2013.

CARNEIRO, S. M. M. A dimensão ambiental da educação geográfica. Educar em Revista, Curitiba, v. 19, p. 39-51, 2002.

CUELLO GIJÓN et al. Orientaciones didáctics para la Educación Ambiental: en E. Primária. Servilla, Espanha: junta de Andalucía, 1992.

DEL RIO, V.; OLIVEIRA, L. Percepção ambiental a experiência brasileira. São Paulo: Studio Nobel, 1999.

DELVAL, J. Introdução à prática do método clínico: descobrindo o pensamento das crianças. Porto Alegre: Artmed, 2002.

GASPAR, J.; MARIAN, A. A percepção do espaço. Revista Portuguesa de Geografia. Lisboa: Finisterra, v. 10, n. 20, 1975.

KOZEL, S. T. Das imagens às linguagens do geográfico: Curitiba, a 'Capital Ecológica'. São Paulo, 2001. Tese (Doutorado em Geografia) Departamento de Geografia da Faculdade de Filosofia, Letras e Ciencias Humanas, Universidade de São Paulo.

MALHADAS, Z. Z. Dupla ação: Conscientização e Educação Ambiental para a Sustentabilidade. Curitiba. Núcleo Interdisciplinar de Meio Ambiente e Desenvolvimento. UFPR, 2001. 
PIAGET, J. A representação do mundo na criança. Rio de Janeiro: Record, 1926.

PIAGET, J. Les mécanismes perceptifs: modèles probabilistes, analyse génétique, relations avec l'intelligence. Paris: PUF, 1961.

PIAGET, J. Development and learning. Journal of Research in Science Teaching. XI, n. 3, 1964.

PIAGET, J. Psicologia da Inteligência. Tradução Egléa de Alencar. Lisboa: Ed. Fundo de Cultura, 1967.

PIAGET. A formação do símbolo na criança. Rio de Janeiro: Zahar Editores, 1975.

PIAGET, J. Tomada de consciência. Tradução Edson Braga de Souza. São Paulo: Melhoramentos da USP, 1977.

PIAGET, J. A Psicologia da criança. Tradução Octavio Mendes Cajado. Rio de Janeiro: Ed. Bertrand, 1989.

PIAGET, J.; INHELDER, B. A representação do espaço na criança. Porto Alegre: Artes Médicas, 1993.

SOUZA, C. L. de. Cognição ambiental e leitura da paisagem urbana: teoria e prática. Cadernos Paisagem/Paisagens. Rio Claro: UNESP, n. 3, p.15-26, mai. 1998.

SUDERHSA. Índice de Qualidade da água do Rio Belém, na Estação à Montante do Parque São Lourenço. Curitiba: Superintendência de Desenvolvimento de Recursos Hídricos e Saneamento Ambiental, 2003.

STOLTZ, T. Interação social e a tomada de consciência da noção lógica. In: GUIMARAES, S.R.K.; STOLTZ, T. (Org.). Tomada de Consciência e conhecimento metacognitivo. Curitiba: UFPR, 2008. p. 111-152.

TUAN, Y. F. Topofilia: um estudo da percepção, atitudes e valores do meio ambiente. São Paulo: Difel, 1980.

VESTENA, C. L. B.; CARNEIRO, S. M. M.; STOLTZ, T. L' education à l' environnement: perception, prise de conscience et conscientisation. Cahier, v.1, n.15, p. 247-253, 2009.

\section{Carla Luciane Blum Vestena}

Doutora em Educação pela Universidade Estadual Paulista Júlio de Mesquita Filho, Mestre em Geografia pela Universidade Federal do Paraná e Graduada em Pedagogia pela Universidade Federal do Paraná. Atualmente é Docente dos Programas de Pós-Graduação em Educação (PPGE) e de Geografia (PPGG) e do Departamento de Pedagogia da Universidade Estadual do Centro-Oeste (UNICENTRO) 
Rua Presidente Zacarias de Goes - até 1508/1509. Santa Cruz. 85015430 Guarapuava, PR - Brasil.

E-mail: clbvestena@gmail.com

\section{Leandro Redin Vestena}

Doutor em Engenharia Ambiental pela Universidade Federal de Santa Caratina, Mestre e Graduado em Geografia pela Universidade Federal do Paraná.

Atualmente é docente permanente e pesquisador do Programa de Pós-Graduação em Geografia e do Departamento de Geografia da Universidade Estadual do Centro-Oeste (UNICENTRO).

Rua Presidente Zacarias de Goes - até 1508/1509. Santa Cruz. 85015430 -

Guarapuava, PR - Brasil.

E-mail: lvestena@gmail.com

Recebido para publicação em março de 2015 Aprovado para publicação em fevereiro de 2016 